\title{
Elaboration of an Instrument to Measure the Construct "Satisfaction with the Training Received"
}

\section{Structural and operational definition, indicators proposal and content validity study}

José A. Lozano-Lozano, Susana Sanduvete-Chaves, Salvador Chacón-Moscoso \& José A. Pérez-Gil

School of Psychology, Seville University, Seville, Spain

Correspondence: Salvador Chacón-Moscoso, Departamento de Psicología Experimental, Facultad de Psicología, Universidad de Sevilla, Campus Ramón y Cajal, C/ Camilo José Cela, s/n. 41018, Sevilla, Spain. Tel: 34-954-557-672. E-mail: schacon@us.es

Received: March 26, 2013 Accepted: April 25, 2013 Available online: May 18, 2013

doi:10.11114/ijsss.v1i2.142 URL: http://dx.doi.org/10.11114/ijsss.v1i2.142

\begin{abstract}
In the context of higher education, one of the relevant elements to assess the quality of service rendered by educational institutions is the assessment that students do in terms of "satisfaction with the training received". Currently, in the literature there are some limitations to determine the main dimensions of the construct "satisfaction with the training received". The aim of this paper is to present evidence of content validity of a set of indicators to measure this construct. After conducting a review of the literature, and based on a questionnaire previously elaborated to measure satisfaction in training programs, a structural and operational definition of the construct was presented, in order to obtain the main dimensions and subdomains that form the construct. Then, a set of indicators were specified to measure each dimension of the construct. Finally, evidence of content validity was obtained carrying out an expert opinion study. As a result, all the indicators presented were suitable or fairly appropriate based on Osterlind indexes about its degree of adjustment with its dimension, and were considered representative. Other evidence of psychometric properties, reliability and validity are planned to be obtained in the future.
\end{abstract}

Keywords: satisfaction with the training received, structural definition, operational definition, construct, indicator, content validity, expert opinion method, Osterlind index

\section{Introduction}

The uncertainty surrounding the construct "satisfaction with the training received" means, among other things, that it is not easy to assess or evaluate, and that there is not an ideal method to assess satisfaction in higher education. However, it is necessary to evaluate it, and the usefulness of this evaluation depends strongly on the cooperation of the human factor involved in the process.

The construct "satisfaction with the training received" is a multidimensional construct, so its measurement has to include several interdependent elements. This fact implies that its diagnosis requires taking into account multiple measures. In this regard, different models that define the construct "satisfaction" through the delimitation and measurement of some dimensions can be found in the literature; e.g., in the European model of quality management (EFQM), appears user's satisfaction as a dimension that delimits the concept "quality", another multidimensional construct (Calvo \& Criado, 2005; Holgado, Chacón, Barbero, \& Sanduvete, 2006). In these models, user's satisfaction appears as one of the key measures of quality, supporting an important trend in quality assessment that considers that it can be defined as the degree in which the expectations of participants have been met. In this context, we consider that the conceptual delimitation of the construct "satisfaction with the training received" is one key step in the development of this work.

In the design of an indicator system, we have to take into account the necessary aspects to obtain an adequate theoretical-conceptual delimitation (Anguera, 1989), the characteristics of the indicator systems (Setién, 1993) 
and the probabilistic relationships of the paradigm or statistical model in which measurement systems stand nowadays (MacCallum, Roznowski, Mar, \& Reith, 1994).

In this sense, Thorndike and Hagen (1989) suggest that the measurement of any construct or attribute always involves three stages: a) Identification and definition of the attribute to be measured; b) Determination of the set of operations through this attribute can be expressed and perceived; and c) Establishment of a set of procedures and definitions to transform the observations into quantitative statements of grade and quantity.

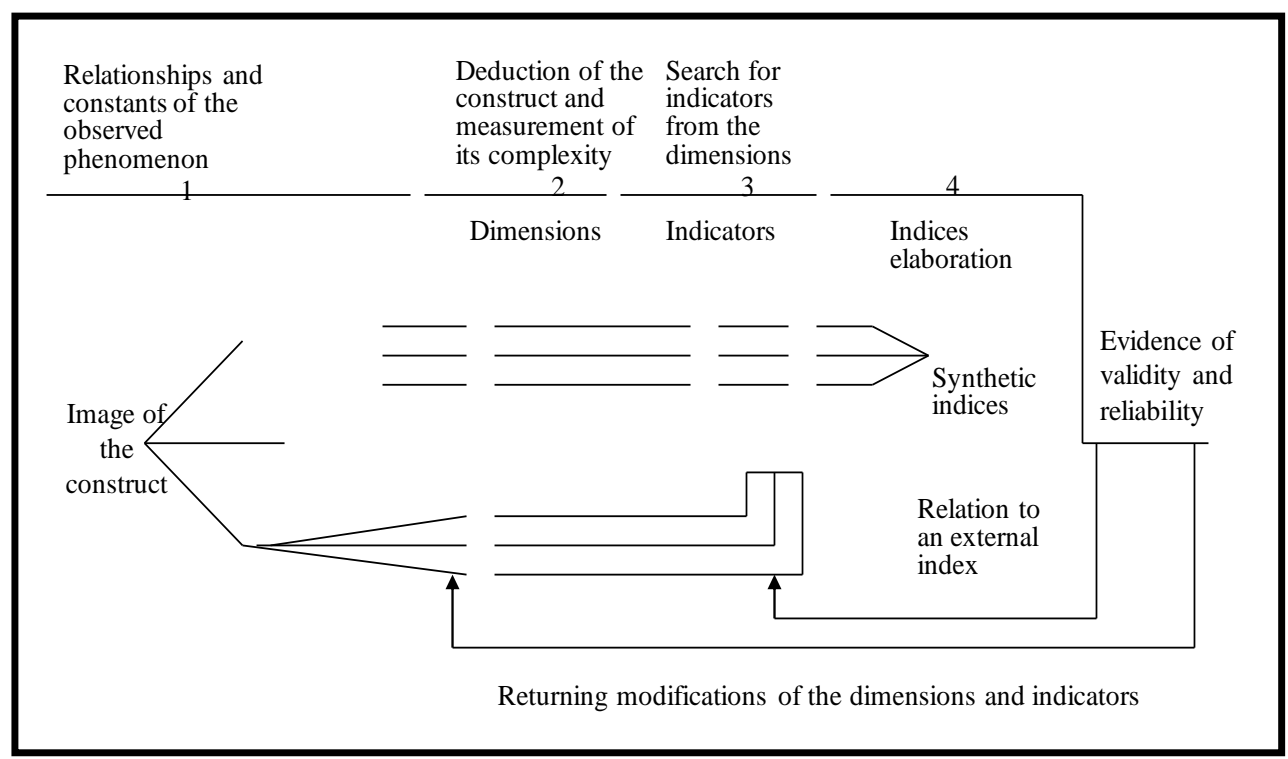

Figure 1. Deductive procedure proposed by Lazarsfeld (1973), adapted from Anguera, Chacón, and Holgado (2008)

In the same way, Figure 1 represents the deductive procedure proposed by Lazarsfeld (1973) to define the construct object of study by obtaining appropriate indicators.

The identification of the objective of the instrument, in general, implies to declare explicitly the construct for what the scores are going to be used. It emphasizes the meaning of the terms used and has the advantages of collaborating to make the objective understandable, and define the construct.

Therefore, any construct to be measured should be defined both structural and operationally (Pérez-Gil, Chacón, \& Moreno, 2000). The structural definition implies to delimit the construct from a substantive and consistent theory that relates this construct with other constructs or empirical variables; in the technique of structural equation models (SEM), it is usually called the structural model. The operational definition implies to make explicit the objective data that can be considered as indicators of the construct, i.e. to specify the semantic or operative aspects of each construct; in the technique of SEM, it is usually called the measurement model (Bollen, 1989).

In short, the measurements used in psychology can respond to a wide variety of objectives and contexts. It is necessary to be aware that each type of goals poses specific demands throughout the process of construction of the instrument. In order to concrete the goals, the characteristics of the population and the type of inferences or uses that is going to be obtained from the instrument have to be taken into account.

Despite its importance, the conceptual definition of the objective is not always delimited, because it is a helpful but not a determining factor to concrete the rest of steps of the construction of the measuring instrument. The way it is applied, its length, the type of items that constitutes it, its degree of difficulty, etc. are aspects that depend on the purpose for which the scores are going to be used.

In sum, following the previously delimitated stages, the construct "satisfaction with the training received" was structural and operationally defined; and after that, concrete indicators were delimitated.

\subsection{Structural Definition of the Construct "Satisfaction with the Training Received"}

The most common variables considered part of the construct "satisfaction with the training received" were determined based on: a) the training satisfaction questionnaire (TSQ), an instrument previously developed to 
measure satisfaction in the context of training programs for workers, with appropriate psychometric characteristics, a second-order factor model and its invariance tested, and evidence of construct validity provided (Holgado et al., 2006; Sanduvete, Holgado, Chacón, \& Barbero, in press); and b) the analysis of the different definitions given and the indicators included in other instruments that measured this construct, obtained in a bibliographic review.

Concretely, these variables were the following:

- Design and general aspects: it refers to the general assessment and global considerations that the participant performs about the formative action. It provides information about the suitability and usefulness of the content, the total duration of the course, its evaluation, and the objectives and methodology according to the level of knowledge of the students.

- Teacher: it refers to the degree of acceptance that participants grant to the teacher. It allows knowing the valuation in terms of his/her didactic abilities, command of techniques and the subject, ability to motivate students and adaptation to the level of knowledge of the students.

- Materials and resources: it collects information about the perception that students have about the resources used during the formative action, if they were adequate and sufficient; as well as information on the quality and adequacy of training materials, instruments of practice, equipment, facilities and classrooms.

- Management and organization: it refers to the opinion that participants have about the training plan/project and people who execute it. This section contains all the aspects related to administrative services and procedures, and the bearing participants receive.

Based on these variables, the construct "satisfaction with the training received" could be determined mainly by the following factors: a) Objectives and contents of the formative action; b) Methodology and climate; c) Global utility or value of the formative action; d) Teaching staff; e) Participation, action and attitude of the students; f) Conditions of the assessment; and g) Organization and external management.

We consider that these elements are included directly or indirectly in any educational project, and could generate differences on the educational progression in general and, therefore, in the "satisfaction with the training received". If we could analyze the results of the training and the characteristics of the students (gender, acquired skills, income level that they can achieve after graduating, etc.), we could establish relations of correspondence in order to value whether the satisfaction with the educational system facilitates, influences or produces improvements in the training received by the target population (criterion validity).

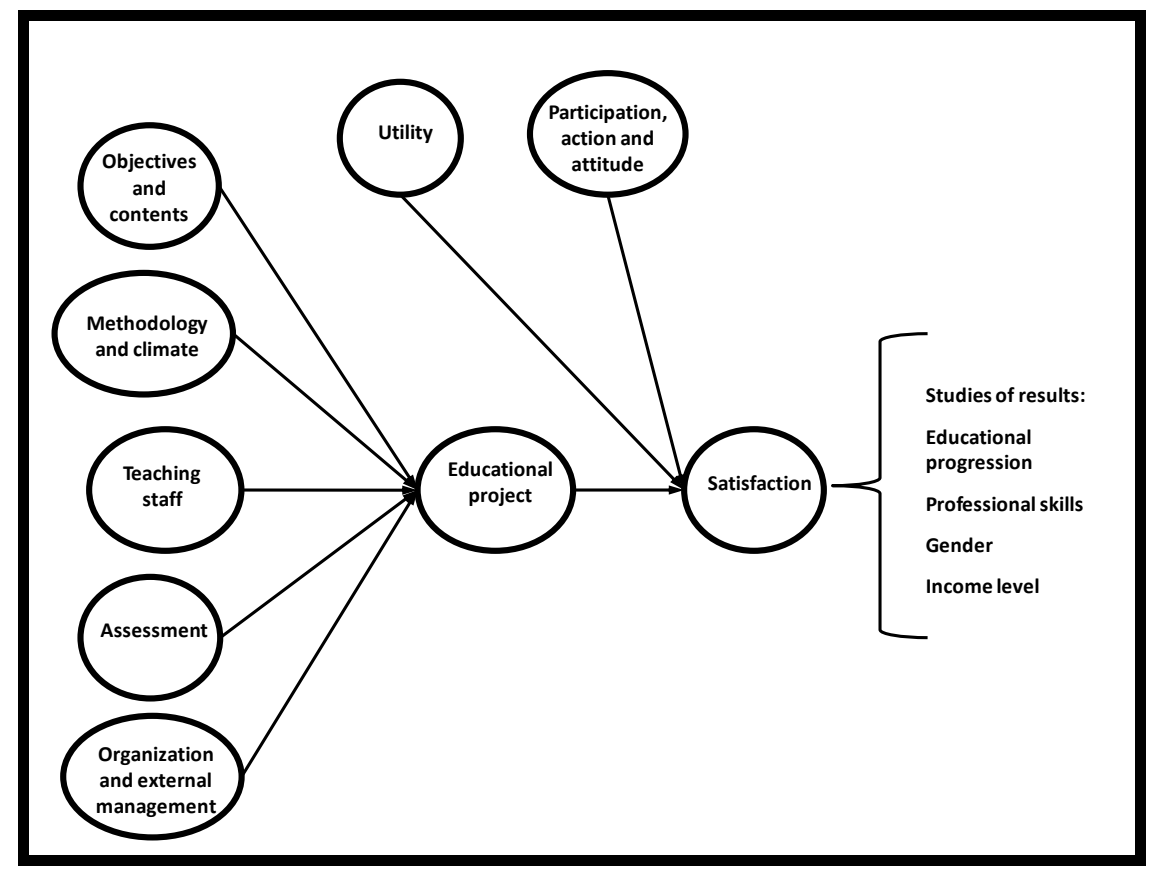

Figure 2. Structural definition of the construct "satisfaction with the training received" 
Figure 2 shows a graphical representation of the structural delineation of the studied construct, which is represented in relation to other no-directly observable constructs (objectives and contents, utility, educational progression, etc.).

\subsection{Operational Definition of the Construct "Satisfaction with the Training Received"}

The operational definition consists of the specification of the dimensions that structure the design of the measuring instrument.

Table 1. Dimensions of the instrument to measure "satisfaction with the training received" and their elements or subdomains

\begin{tabular}{|c|c|}
\hline Dimension & Elements or sub-domains \\
\hline \multirow{3}{*}{ 1. Objectives and contents } & Clarity of the objectives \\
\hline & Clarity of the topic \\
\hline & Clarity of the contents \\
\hline \multirow{3}{*}{ 2. Methodology and climate } & Teaching methods \\
\hline & Materials \\
\hline & Climate conditions \\
\hline \multirow{2}{*}{ 3. Utility } & Utility for professional work \\
\hline & Utility for personal experience \\
\hline \multirow{5}{*}{ 4. Teaching staff } & Domain of matter \\
\hline & Motivate and arouse interest \\
\hline & Monitoring guidelines \\
\hline & Pace \\
\hline & Readiness to help \\
\hline \multirow{3}{*}{$\begin{array}{l}\text { 5. Participation, action and attitude } \\
\text { of students }\end{array}$} & Attitude of interest and involvement \\
\hline & Expectations \\
\hline & Marks \\
\hline \multirow{2}{*}{ 6. Assessment } & $\begin{array}{l}\text { Rules of the assessment proposed (e.g., elaboration } \\
\text { of materials by students or attendance control) }\end{array}$ \\
\hline & Time allocated \\
\hline \multirow{3}{*}{$\begin{array}{l}\text { 7. Organization and external } \\
\text { management }\end{array}$} & Conditioning studies rooms \\
\hline & Availability of computer classrooms \\
\hline & Administrative office \\
\hline
\end{tabular}

Table 1 presents the dimensions that were considered in the elaboration of the instrument to measure "satisfaction with the training received", and their elements or subdomains.

In dimension 1 "Objectives and contents", the objectives refer to the goals that students have to achieve in the subject; the contents are the topic that composes the subject and its development; in all the cases, their clarity is measured.

Dimension 2 "Methodology and climate" collects information about the teaching methods and the resources available during the training received allowing to assess whether they were adequate and sufficient, as well as information on the quality and adequacy of the didactic materials, equipment and materials of practice, facilities and classrooms used.

Dimension 3 "Utility" is the perception that students have about the possible application of the learned contents to the professional practice and the personal experience.

Dimension 4 "Teaching staff" includes content relative to the competence of the teachers, the pertinence of their 
monitoring guidelines to the students, their level of commitment with the students, and the quality of their training. It allows knowing the valuation in relation to their teaching abilities, mastery of techniques, knowledge of the subject, ability to engage students, and whether teachers conform to the level of the students.

Dimension 5 "Participation, action and attitude of students" includes contents relative to the motivation of the students with the subject and their evaluation, and the perception of the difficulty or ease of the project, intellectual benefits and academic advantages.

Dimension 6 "Assessment" is about the rules of the assessment proposed by the teacher, such as the elaboration of questions by the students, or the compulsory attendance; and the time allocated to this assessment.

Dimension 7 "Organization and external management" includes contents relative to the infrastructure necessary for the proper execution of the planned activities: the support provided by the auxiliary services; the existence of easy access to the computerized classrooms; or the effectiveness of the administrative procedures.

\subsection{Indicators Proposal}

Table 2. Proposal of the dimensions and their indicators to assess "satisfaction with the training received"

\begin{tabular}{|c|c|c|}
\hline Dimension & Indicators proposed & Indicator \\
\hline \multirow{3}{*}{$\begin{array}{l}\text { 1. Objectives and } \\
\text { contents }\end{array}$} & Objectives proposed are clear & 01 \\
\hline & The topic is clear & 02 \\
\hline & The contents are clear & 03 \\
\hline \multirow{3}{*}{$\begin{array}{l}\text { 2. Methodology and } \\
\text { climate }\end{array}$} & The teaching methodology is appropriate & 04 \\
\hline & $\begin{array}{l}\text { The materials proposed are appropriate for the understanding of the } \\
\text { contents (slides, web page, recommended readings and exercises) }\end{array}$ & 05 \\
\hline & $\begin{array}{l}\text { Environmental conditions are adequate (facilities, classrooms, } \\
\text { equipment) }\end{array}$ & 06 \\
\hline \multirow[b]{2}{*}{ 3. Utility } & The knowledge acquired is useful for my specific job & 07 \\
\hline & $\begin{array}{l}\text { The knowledge acquired is realistic and practical for my personal } \\
\text { development }\end{array}$ & 08 \\
\hline \multirow{3}{*}{ 4. Teaching staff } & Professor communicates in a clear way, easy to understand & 09 \\
\hline & Professor dominates the area & 10 \\
\hline & $\begin{array}{l}\text { The doubts and questions on aspects of the subject have been properly } \\
\text { addressed by the professor }\end{array}$ & 11 \\
\hline \multirow{2}{*}{$\begin{array}{l}\text { 5. Participation, } \\
\text { action and attitude of } \\
\text { students }\end{array}$} & $\begin{array}{l}\text { The grade obtained in the subject reflects adequately the effort that has } \\
\text { been done }\end{array}$ & 12 \\
\hline & This subject has helped to develop self-learning strategies on students & 13 \\
\hline \multirow{3}{*}{ 6. Assessment } & $\begin{array}{l}\text { The evaluation system followed in this subject is suitable (internal } \\
\text { organization: assessments, attendance, participation, defense, personal } \\
\text { work) }\end{array}$ & 14 \\
\hline & $\begin{array}{l}\text { The evaluation system followed in this subject has increased the interest } \\
\text { in the matter }\end{array}$ & 15 \\
\hline & The time devoted to the study of this subject is appropriate & 16 \\
\hline \multirow{3}{*}{$\begin{array}{l}\text { 7. Organization and } \\
\text { external management }\end{array}$} & The study rooms of our faculty are adequately prepared & 17 \\
\hline & The computer rooms of our faculty are properly prepared & 18 \\
\hline & $\begin{array}{l}\text { The administrative office coordinates properly the groups for the } \\
\text { students }\end{array}$ & 19 \\
\hline
\end{tabular}

Based on the structural and operational definition of the construct, the next stage was to propose specific indicators of measurement. After carrying out Mini-Delphi discussion groups with experts, indicators were written and grouped in the defined dimensions. The result is presented in Table 2.

Then, the following necessary stage was to provide evidence of the quality of this system of indicators, one of the criteria refers to its validity, related to the degree in which this system measures the construct which it was created for.

The validity of a system of indicators implies establishing reasonable judgments about the degree in which the evidence obtained with that system allow taking actions based on the developed measurement model (Messick, 1989). 
It makes no sense to question if the system of indicators is valid in itself regardless of the objective of the research or the context. In this sense, there is no a single procedure which reports data about the validity of systems of indicators, but that data to establish judgments about its validity are given by the results obtained combining different techniques (triangulation), by empirical evidence based on previous experiences and the utility that presents for the proposed measurement model.

The review of the individual quality of each element or indicator that composes a measuring instrument involves obtaining descriptive and statistic information, referred to the technical quality of its elements and generally assumes obtaining evidence of validity, i.e. signs about its relevance, adequacy, clarity, etc.

In accordance with this, it is necessary to provide different validity evidence to the proposed indicators, in particular: a) Content validity, to ensure that the selected indicators constitute a representative sample of all the possible indicators that could have been used; b) Construct validity, to guarantee the existence of the construct that the set of indicators try to measure, and gives meaning to the scores obtained on the instrument through their indicators; and c) Criterion validity, to determine that the scores of the system of indicators are properly related to external criteria of interest (Suen, 1990).

The aim of this paper is to present evidence of content validity of the previously delimited set of indicators to measure the construct "satisfaction with the training received"; the obtaining of evidence of the other kinds of validity is planned for the future.

The fundamental aspects to measure when carrying out a content validity study are (Crocker \& Algina, 1986; Messik, 1975, cited in Pérez et al., 2000): a) Relevance: enhance that all the indicators are part of the previously defined domain; and b) Representativeness: determine that they constitute a representative sample of the universe of possible indicators (Martínez-Arias, 1995).

\section{Method}

\subsection{Participants}

We used intentional sampling: students enrolled in 2 day-shift and 2 evening-shift concrete practice groups of the subject Psychometrics (third year of the degree in Psychology) during the academic year 2009/2010, were requested to collaborate in this task as experts; concretely, 187 students responded to the instrument on the content of the construct "satisfaction with the training received", being the $70.57 \%$ of the total 265 enrolled.

\subsection{Materials}

The instrument fulfilled by experts was Table 2: the system of indicators to measure the construct "satisfaction with the training received", with 19 indicators distributed in 7 dimensions.

A column was added with a 5-point rating scale for each indicator, where experts marked the degree of adjustment indicator-dimension, from 1 "completely disagree" to 5 "completely agree".

The classical proposal (Osterlind, 1989), consists in presenting 3-point rating scales to gather the answers of judges; nevertheless, the rating scales used in this case presented 5 points in order to be more restrictive when considering adequate an indicator, based on a previous study (Sanduvete, Chacón, Sánchez, \& Pérez, in press) that concluded that it is more difficult to find appropriate congruence indexes when using a 5-point rating scale; i.e., all the indicators obtained lower Osterlind indexes when using 5-point rating scales comparing with 3-point ones.

The general instructions of the instrument were as follows: A list of 19 indicators to measure the construct "satisfaction with the training received" is presented below grouped in different dimensions. Please, punctuate from 1 "completely disagree" to 5 "completely agree" the degree of adjustment of each indicator with the dimension it belongs to.

Furthermore, the following free-response question was included in the end: If necessary, write a new indicator to measure the construct, and concrete the dimension in which you would include it.

\subsection{Procedure}

During the academic year 2008/2009, the instrument was included in the institutional platform, concretely in the section "Contents" of the subject Psychometrics. It was available for all the students of 4 practice groups during the academic year 2009/10, and was fulfilled online.

To assess the relevance of the indicators, experts were requested their judgments of opinion regarding the degree of congruence indicator-dimension (Martínez-Arias, 1995). Osterlind (1989) proposed an index to quantify this degree of congruence. Its formal expression is as follows: 


$$
I_{i k}=\frac{(N-1) \sum_{k=1}^{n} X_{i j k}+N \sum_{k=1}^{n} X_{i j k}-\sum_{k=1}^{n} X_{i j k}}{2(N-1) n}
$$

Where,

$N$ refers to the number of dimensions that form the instrument (in this case, 7 dimensions: objectives and contents; methodology and climate; utility; teaching staff; participation, action and attitude of students; assessment; and organization and external management).

$n$ refers to the number of judges who assess the indicator.

$X_{i j k}$ is the score given to the indicator $i$ of the dimension $j$ by the expert $k$.

When the agreement between judges is total, Osterlind index is 1 . When the value is higher than .7 , the indicator is considered suitable; values between .5 and .7 indicates that the indicator is fairly appropriate; finally, with values lower than .5, the indicator is considered inadequate (Osterlind, 1989).

To assess the representativeness of the indicators, the answers given to the free-response question were analyzed.

\section{Results}

Table 3. Distribution of responses and values of the Osterlind index for each indicator

\begin{tabular}{ccccccccc}
\hline Dimension & Indicator & $\% 1$ & $\% 2$ & $\% 3$ & $\% 4$ & $\% 5$ & $\% 6$ & Osterlind \\
\hline \multirow{2}{*}{ 1. Objectives and } & 01 & 3.2 & 2.7 & 6.4 & 48.1 & 39.6 & .00 & .82 \\
contents & 02 & .00 & 2.1 & 4.3 & 35.8 & 57.8 & .00 & .91 \\
& 03 & .00 & .5 & 2.7 & 40.1 & 56.7 & .00 & .96 \\
\hline \multirow{2}{*}{ 2. Methodology } & 04 & .00 & 4.3 & 7.0 & 46.5 & 42.2 & .00 & .84 \\
and climate & 05 & .50 & 2.1 & 5.3 & 37.5 & 54.6 & .00 & .89 \\
& 06 & .00 & 3.2 & 27.8 & 44.9 & 24.1 & .00 & .66 \\
\hline \multirow{2}{*}{ 3. Utility } & 07 & .50 & 1.1 & 8.0 & 45.5 & 44.9 & .00 & .89 \\
& 08 & 1.6 & .5 & 10.7 & 54.6 & 32.6 & .00 & .85 \\
\hline & 09 & .00 & 1.1 & 4.3 & 27.2 & 67.4 & .00 & .94 \\
4. Teaching staff & 10 & .00 & .50 & 3.7 & 33.8 & 62.0 & .00 & .95 \\
& 11 & .50 & .50 & 2.7 & 36.4 & 59.9 & .00 & .95 \\
\hline 5. Participation, & 12 & .50 & 2.1 & 7.5 & 40.6 & 48.8 & .50 & .87 \\
action and attitude & 13 & .00 & 2.7 & 3.7 & 34.2 & 59.4 & .00 & .91 \\
of students & & & & & & & & .78 \\
\hline & 14 & 1.1 & 3.2 & 13.3 & 41.2 & 41.2 & .00 & .60 \\
6. Assessment & 15 & 3.7 & 6.4 & 19.3 & 46.0 & 24.6 & .00 & .60 \\
\hline 7. Organization & 16 & 1.6 & 8.0 & 20.9 & 52.9 & 16.6 & .00 & .85 \\
and external & 18 & .00 & 1.1 & 12.8 & 49.7 & 36.4 & .00 & .87 \\
management & 19 & 1.1 & 1.1 & 8.0 & 34.2 & 55.6 & .00 & .88 \\
\hline
\end{tabular}

Table 3 reflects, for each indicator, the percentage of response obtained in each option about the degree of adjustment indicator-dimension: 1 refers to "completely disagree"; 2 , "disagree"; 3 , "neither agree nor disagree"; 4, "agree"; and 5, "completely agree"; 6 presents the omissions. Finally, last column shows the Osterlind index.

The most chosen options were 4 "agree" and 5 "completely agree". The indicator that obtained most frequently the highest punctuation was the indicator 9 "professor communicates in a clear way, easy to understand" $(67.4 \%$ of the experts gave the value 5). Only indicators 6 "environmental conditions are adequate (facilities, classrooms, equipment)" and 16 "the time devoted to the study of this subject is appropriate" obtained the option 3 "neither agree nor disagree" in more than $20 \%$ of the cases.

In terms of the values of Osterlind index, most of the indicators (16 indicators, the $84.21 \%$ of the total) obtained values greater than .7, oscillating in an interval between .78-.96; i.e. presented appropriate indexes. Only 3 of them (indicators 6,15 and 16, the $15.79 \%$ of the total) obtained moderately appropriate values, between .5 and .7 
(concretely, their values were in the interval .6-.66). None of the indicators presented inadequate values.

Table 4. Descriptive statistics of the different indicators

\begin{tabular}{ccccccccccccc}
\hline Indicator & 01 & 02 & 03 & 04 & 05 & 06 & 07 & 08 & 09 & 10 \\
\hline Mean & 4.18 & 4.49 & 4.53 & 4.27 & 4.43 & 3.90 & 4.33 & 4.16 & 4.61 & 4.57 \\
Median & 4 & 5 & 5 & 4 & 5 & 4 & 4 & 4 & 5 & 5 \\
Mode & 4 & 5 & 5 & 4 & 5 & 4 & 4 & 4 & 5 & 5 \\
\hline Indicator & 11 & 12 & 13 & 14 & 15 & 16 & 17 & 18 & 19 \\
\hline Mean & 4.65 & 4.33 & 4.50 & 4.18 & 3.81 & 3.75 & 4.21 & 4.34 & 4.42 \\
Median & 5 & 4 & 5 & 4 & 4 & 4 & 4 & 4 & 5 \\
Mode & 5 & 5 & 5 & $4-5$ & 4 & 4 & 4 & 5 & 5 \\
\hline
\end{tabular}

Table 4 presents the descriptive statistics obtained from the different indicators. The mode shows that all of them were valued in their responses of adequacy with options 4 or 5 by the majority of the students. 10 of the indicators $(52.63 \%)$ were valued mostly with the option 5 "completely agree"; 8 of them $(42.11 \%)$ obtained mainly the valuation 4 "agree"; 1 indicator (5.26\%), concretely indicator 14, was bimodal (with values 4 and 5 ).

In addition, all the indicators presented means between 4 and 5, or close; concretely, the highest mean was 4.65 , obtained by the indicator 11 "The doubts and questions on aspects of the subject have been properly addressed by the professor"; and the lowest mean was 3.75 , obtained by the indicator 16 "The time devoted to the study of this subject is appropriate".

Finally, the median was 4 in 11 indicators (the $57.89 \%$ of all the cases), and 5 in 8 indicators (42.11\%).

Apart from this, nobody answered the free-response question; i.e. no one considered necessary the inclusion of a new indicator to measure appropriately the construct.

\section{Discussion}

Our starting point was the structural and operational definition obtained from a questionnaire to measure satisfaction in training programs for workers previously elaborated; and from other definitions and instruments that measured the construct, obtained in a theoretical literature review. Then, based on the results obtained in Mini-Delphi discussion groups with experts, a set of indicators to measure the dimensions of the construct was proposed.

The appropriate results obtained in the content validity study supported the suitability of the selected indicators, because the different indicators were consistent in terms that obtained adequate values of Osterlind index. These results can be considered an evidence of the relevance of the indicators.

The representativeness of the indicators was also considered appropriate, taking into account that no expert proposed any new indicator necessary to measure correctly the construct.

We consider that this procedure makes possible the use of this instrument to measure the "satisfaction with the training received" in students enrolled in the different subjects in the degree of Psychology.

This work is only considered the first step to obtain a definitive instrument to measure the "satisfaction with the training received" in high education. More steps are planned to be taken in order to increase evidence of the quality of this measuring instrument: studies about its psychometric properties; reliability; construct, criterion, convergent and discriminant validity; and invariance in order to generalize the use of this measuring instrument to other contexts, are planned to be carried out soon.

\section{Acknowledgements}

The present study forms part of the results obtained in teaching innovation project "Design of an instrument for assessing satisfaction with educational programs and projects of the degree in Psychology", funded by the University of Seville, Spain; and in research project PSI2011-29587, funded by the Spanish Ministry of Science and Innovation. 


\section{References}

Anguera, M. T. (1989). Metodología de la observación en las Ciencias Humanas [Methodology of the observation in Human Sciences]. Madrid, Spain: Cátedra.

Anguera, M. T., Chacón, S., \& Holgado, F. P. (2008). Indicadores en evaluación de programas. In M. T. Anguera, S. Chacón, \& A. Blanco (Eds.), Evaluación de programas sociales y sanitarios. Un abordaje metodológico [Social and health program evaluation. A methodological approach] (pp. 103-126). Madrid, Spain: Síntesis.

Bollen, K. A. (1989). Structural equations with latent variables. New York, NY: Wiley.

Calvo, A., \& Criado, F. (2005). Analysis of the European excellence model's validity for quality management in university institutions: a management approach. Revista Europea de Dirección y Economía de la Empresa, 14, 41-58. Retrieved from http://dialnet.unirioja.es/servlet/listaarticulos?tipo_busqueda=EJEMPLAR\&revista_busqueda=1231\&clave _busqueda $=126313$

Crocker, L., \& Algina, J. (1986). Introduction to classical and modern test theory. Belmont, CA: Wadsworth.

Holgado, F. P., Chacón, S., Barbero, M. I., \& Sanduvete, S. (2006). Training satisfaction rating scale: Development of a measurement model using polychoric correlations. European Journal of Psychological Assessment, 22, 268-279. http://dx.doi.org/10.1027/1015-5759.22.4.268

Lazarsfeld, P. (1973). De los conceptos a los índices empíricos. In R. Boudon, \& P. Lazarsfeld, Metodología de las Ciencias Sociales. Conceptos e indices [Methodology of the Social Sciences. Concepts and indexes]. Barcelona, Spain: Laia.

MacCallum, R. C., Roznowski, M., Mar, C. M., \& Reith, J. V. (1994). Alternative stretegies for cross validation of covariance structure models. Multivariate Behavioral Research, 29, 1-32. http://dx.doi.org/10.1207/s15327906mbr2901_1

Martínez-Arias, R. (1995). Psicometría: teoría de los tests psicológicos y educativos [Psychometrics: Theory of the psychological and educational tests]. Madrid, Spain: Síntesis.

Messick, S. (1975). The standard problem: Meaning and values in measurement and evaluation. American Psychologist, 30, 955 -966.

Messick, S. (1989). Validity. In R. L. Linn (Ed.), Educational measurement (pp. 13-103). New York, NY: Macmillan.

Osterlind, S. J. (1989). Constructing test items. Boston, MA: Kluwer. http://dx.doi.org/10.1007/978-94-009-1071-3_1

Pérez-Gil, J. A., Chacón, S., \& Moreno, R. (2000). Construct validity: The use of factor analysis. Psicothema, 12, 442-446. Retrieved from http://www.psicothema.com/pdf/601.pdf

Sanduvete, S., Chacón, S., Sánchez, M., \& Pérez, J. A. (in press). The revised Osterlind index. A comparative analysis in content validity studies. Acción Psicológica.

Sanduvete, S., Holgado, F. P., Chacón, S., \& Barbero, M. I. (in press). Measurement invariance study in the Training Satisfaction Questionnaire (TSQ). Spanish Journal of Psychology, 16.

Setién, M. L. (1993). Indicadores sociales de calidad de vida [Social indicators of quality of life]. Madrid, Spain: Siglo XXI.

Suen, H. K. (1990). Principles of test theories. Hillsdale, NJ: Lawrence Erlbaum.

Thorndike, R. L., \& Hagen, E. P. (1989). Medición y evaluación en psicología y educación [Measurement and evaluation in psychology and education]. México, DF: Trillas.

\section{$($ cc) $\mathrm{EY}$}

This work is licensed under a Creative Commons Attribution 3.0 License. 